OPEN ACCESS

Edited by:

Ghulam Jeelani,

The University of Tokyo, Japan

Reviewed by:

Yumiko Saito-Nakano,

National Institute of Infectious

Diseases (NIID), Japan

Vahab Ali,

Indian Council of Research, India

Emma Saavedra,

Instituto Nacional

de Cardiología, Mexico

${ }^{*}$ Correspondence:

Shannon Moonah

sm5fe@virginia.edu

Specialty section:

This article was submitted to

Clinical Microbiology,

a section of the journal

Frontiers in Cellular and

Infection Microbiology

Received: 24 November 2020

Accepted: 18 February 2021

Published: 11 March 2021

Citation:

Shirley D-A, Sharma I, Warren CA and Moonah S (2021) Drug Repurposing of

the Alcohol Abuse Medication

Disulfiram as an Anti-Parasitic Agent.

Front. Cell. Infect. Microbiol. 11:633194.

doi: 10.3389/fcimb.2021.633194

\section{Drug Repurposing of the Alcohol Abuse Medication Disulfiram as an Anti-Parasitic Agent}

\author{
Debbie-Ann Shirley ${ }^{1}$, Ishrya Sharma ${ }^{2}$, Cirle A. Warren ${ }^{2}$ and Shannon Moonah ${ }^{2 *}$ \\ ${ }^{1}$ Division of Pediatric Infectious Diseases, Department of Pediatrics, University of Virginia, Charlottesville, VA, United States, \\ ${ }^{2}$ Division of Infectious Diseases \& International Health, Department of Medicine, University of Virginia, Charlottesville, \\ VA, United States
}

Parasitic infections contribute significantly to worldwide morbidity and mortality. Antibiotic treatment is essential for managing patients infected with these parasites since control is otherwise challenging and there are no vaccines available for prevention. However, new antimicrobial therapies are urgently needed as significant problems exist with current treatments such as drug resistance, limited options, poor efficacy, as well as toxicity. This situation is made worse by the challenges of drug discovery and development which is costly especially for non-profitable infectious diseases, time-consuming, and risky with a high failure rate. Drug repurposing which involves finding new use for existing drugs may help to more rapidly identify therapeutic candidates while drastically cutting costs of drug research and development. In this perspective article, we discuss the importance of drug repurposing, review disulfiram pharmacology, and highlight emerging data that supports repurposing disulfiram as an anti-parasitic, exemplified by the major diarrheacausing parasite Entamoeba histolytica.

Keywords: drug development, parasites, protein degradation, drug repurposing and repositioning, disulfiram (Antabuse)

\section{INTRODUCTION}

Protozoan parasites cause more than one million deaths annually, disproportionately affecting poverty-stricken areas of the world (Murray et al., 2012; Torgerson et al., 2015; De Rycker et al., 2018). Of these, Plasmodium falciparum, which causes human malaria, is responsible for over 618,000 of these deaths each year, while Leishmania, which causes visceral leishmaniasis, a febrile disease marked clinically by fatal visceromegaly if untreated, falls in line after with the second highest mortality among tropical diseases (Weiss et al., 2019). Entamoeba histolytica, which causes amebic colitis and amebic liver abscesses, infects millions worldwide and kills more than 50,000 people each year (Lozano et al., 2012; Shirley et al., 2018). Other protozoan parasites, such as Toxoplasma gondii, which infect up to a third of the world's population and causes devastating 
congenital infection, continue to pose a serious threat to health, especially among the world's poorest populations. The global, social and economic impact of these neglected diseases including trypanosome infections is untold. Antibiotic treatment is essential for managing patients infected with these protozoan parasites, but therapeutic options are severely limited due to the cost, poor efficacy, drug resistance and toxicity associated with currently available therapies. Discovery of new treatment is therefore urgently needed (De Rycker et al., 2018).

\section{SIGNIFICANCE OF AMEBIASIS AND WHY NEW TREATMENT OPTIONS ARE NEEDED}

To examine in more detail some of the limitations faced in treating protozoan parasitic disease, the case of amebiasis provides a good example. Amebic colitis is a leading cause of severe diarrhea worldwide and is listed among the top 15 causes of diarrhea in the first 2 years of life and a top seven cause of dysentery in children under five years (Kotloff et al., 2013; Liu et al., 2016; Shirley et al., 2018). Multiple areas throughout the world continue to observe prevalence rates of amebiasis of over $10 \%$ (Shirley et al., 2018). Severe forms of amebic colitis are associated with high mortality, and on average around half with severe colitis die (Shirley and Moonah, 2016). Immigration, travel and sexual transmission are leading to re-emergence of amebiasis in developed settings (Hung et al., 2012; Cordel et al., 2013; Van Den Broucke et al., 2018).

Only one class of drugs (the nitroimidazoles, such as metronidazole) are available to effectively treat invasive forms of disease, with little progress made in new drug development over the past 60 years (Marie and Petri, 2013; Gonzales et al., 2019). No alternative therapies exist for those who experience toxicity from metronidazole, such as neurologic and dermatologic effects (Woodruff et al., 2002; Kumar et al., 2013; Mazumdar and Shome, 2014; Sørensen et al., 2018; Cappellari et al., 2020). This is illustrated in a recent report from Japan of two patients with ulcerative amebic colitis who received substandard therapy due to not being able to take metronidazole because of side effects (Yamamoto et al., 2020). Additionally, there are no treatment options if metronidazole resistance develops (Shirley et al., 2018; Kumanan et al., 2020). Clinical use of metronidazole, both appropriate and inappropriate, is widespread with metronidazole ranking amongst the most commonly used antibiotics for diarrhea worldwide. (Rogawski et al., 2017). There are concerns that high antibiotic pressure will give rise to resistance with amebiasis. Resistance to metronidazole has already been documented among other similar anaerobic protists Trichomonas vaginalis and Giardia lamblia (Schwebke and Barrientes, 2006; Kirkcaldy et al., 2012; Paulish-Miller et al., 2014). Along with the ease with which resistant amebic strains can be generated in the laboratory raises concerns that it is only a matter of time before drug resistant amebiasis emerges (Leitsch, 2015; Ehrenkaufer et al., 2018). We are ill-prepared for scenarios like resistance; therefore, new anti- amebic therapies are called for (Shirley et al., 2019). Innovative solutions, like drug repurposing will help meet this need.

\section{THE IMPORTANCE OF DRUG REPURPOSING}

Drug repurposing, also known as drug repositioning, reprofiling, or re-tasking, involves identifying new uses of already approved, discontinued, or investigational drugs outside of the original indication. New drug discovery and development is a slow, arduous, and costly process that is further hampered by high failure rates. As protozoan parasitic infections are diseases of the poor, global investments are inadequate, though improving, for disease control. Repurposing of old drugs hence serves as an appealing alternative strategy to lower cost and save time. It is estimated that the cost of repurposing a drug is about one-tenth that of the 2-3 billion dollar investment commonly required in the development of a new drug. The regulatory process is additionally simplified if the safety, formulation, and pharmacokinetic data essential in preclinical and early clinical safety studies to bring a drug to market have been completed, allowing resources to be focused on the more advanced phases of efficacy trial studies. Often bulk manufacturing has already been established as well (Andrews et al., 2014; Farha and Brown, 2019; Pushpakom et al., 2019). Well-known examples of repurposed drugs include sildenafil, an antihypertensive drug repurposed for erectile dysfunction treatment and miltefosine, an anti-neoplastic agent repurposed for leishmaniasis (Fink et al., 2002; Braga, 2019). Here we share the perspective of repurposing disulfiram as an antiparasitic agent. Other compounds with potential anti-amebic effects have been well-reviewed elsewhere (Debnath et al., 2013; Andrade and Reed, 2015; Jeelani and Nozaki, 2016; MartínezCastillo et al., 2018; Nagaraja and Ankri, 2019).

\section{DISULFIRAM}

Disulfiram, or tetraethylthiuram disulfide (Antabuse), is an FDA-approved drug that has been used to treat alcohol dependence for the past seven decades, with well-established pharmacokinetic properties, safety, and tolerance (Table 1) (Johansson, 1992; Suh et al., 2006).

The discovery of disulfiram relates back to a series of chance discoveries. Initially used as a compounding agent to accelerate the manufacturing process of rubber production in the $18^{\text {th }}$ century, it was noted in 1937 by an American chemical plant physician that workers exposed to disulfiram became intolerable to alcohol consumption (Suh et al., 2006; Kragh, 2008). Later, Danish researchers exposed to disulfiram while investigating its vermicidal properties, noted that disulfiram changed the effect of alcohol to an unpleasant experience, prompting collaborative efforts to investigate disulfiram as a therapeutic agent aimed to deter alcohol consumption. Disulfiram was subsequently approved by the US Food and Drug Administration for treatment of alcoholism in 1951 (Suh et al., 2006; Kragh, 2008; 
TABLE 1 | Overview of Disulfiram.

\begin{tabular}{|c|c|}
\hline Name & $\begin{array}{l}\text { Disulfiram, or tetraethylthiuram disulfide } \\
\text { (Antabuse) }\end{array}$ \\
\hline FDA approval & 1951 \\
\hline $\begin{array}{l}\text { FDA approved } \\
\text { indication }\end{array}$ & Alcohol Use Disorder \\
\hline $\begin{array}{l}\text { Mechanism of } \\
\text { Action }\end{array}$ & Aldehyde dehydrogenase inhibitor \\
\hline $\begin{array}{l}\text { Potential repurposed } \\
\text { indications } \\
\text { (not FDA-approved) }\end{array}$ & $\begin{array}{l}\text { Anti-neoplastic } \\
\text { Anti-microbial }\end{array}$ \\
\hline Metabolites & $\begin{array}{l}\text { Diethyldithiocarbamate, diethyldithiomethylcarbamate, } \\
\text { carbon disulfide, dimethylamine, and divalent metal } \\
\text { complexes such as zinc ditiocarb (ZnDTC) }\end{array}$ \\
\hline FDA prescribing & $250(125-500) \mathrm{mg} / \mathrm{day}$ \\
\hline Route & By mouth \\
\hline Elimination & Metabolites excreted mainly by kidney, feces and lung \\
\hline Adverse events & $\begin{array}{l}\text { Disulfiram-alcohol reaction, hepatotoxicity, neuropathy, } \\
\text { psychosis }\end{array}$ \\
\hline $\begin{array}{l}\text { Examples of drug } \\
\text { interactions }\end{array}$ & $\begin{array}{l}\text { Metronidazole, alcohol and alcohol-containing } \\
\text { medications, phenytoin, anticoagulants e.g. warfarin, } \\
\text { amitriptyline, isoniazid, diazepam }\end{array}$ \\
\hline Contra-indications & $\begin{array}{l}\text { Concurrent alcohol use, hypersensitivity to disulfiram or } \\
\text { thiuram derivatives }\end{array}$ \\
\hline Special populations & $\begin{array}{l}\text { Safety in pregnant or nursing mothers and children has } \\
\text { not been established. }\end{array}$ \\
\hline
\end{tabular}

FDA, US Food and Drug Administration.

De Sousa, 2019). It is now understood that the disulfiram-alcohol reaction is due to the inhibition of aldehyde dehydrogenase, increasing the levels of acetaldehyde in the blood and leading to disagreeable physical effects such as flushing, sweating and headache upon consuming alcohol. Collectively, studies evaluating the efficacy of disulfiram have yielded variable results, likely related to limitations in study methods, such as small sample sizes, lack of randomization, unmasked design, short follow-up periods, and inability to measure treatment adherence. Disulfiram remains a recommended deterrent that can be safely used in motivated and well-informed patients wishing to abstain from alcohol (Skinner et al., 2014; Reus et al., 2018).

\section{Dosage and Frequency}

Using the FDA-approved indication of management of chronic alcohol use, patients may be given a dose of $250 \mathrm{mg}$, to be taken by mouth once daily, with a maximum dosage of $500 \mathrm{mg} /$ day. Newer off label uses describe administration of disulfiram 500 $\mathrm{mg}$ daily plus zinc gluconate $50 \mathrm{mg}$ three times daily or copper gluconate $2 \mathrm{mg}$ three times daily in combination therapy (Ekinci et al., 2019).

\section{Absorption, Distribution, and Excretion}

Approximately $80-95 \%$ of ingested disulfiram is absorbed and is more efficiently dissolved in the gastric juice as an effervescent tablet; fractions that are unabsorbed are excreted. In the body, disulfiram is rapidly metabolized to diethyldithiocarbamic acid (ditiocarb, DTC) which then quickly forms diethylthiocarbamic acid methyl ester (MeDTC) or is broken down into carbon disulfide and dimethylamine. MeDTC is the metabolite mainly responsible for the alcohol effects by inhibiting acetaldehyde dehydrogenase. DTC is a strong metal chelating substance that forms complexes with metal ions, for example in the presence of the metal ion zinc, forms zinc-ditiocarb complex (ZnDTC). Disulfiram is also reduced to DTC in the stomach where it can form metal ion complexes in the gastrointestinal tract. DTC-metal complexes have a relatively long half-life, are widely distributed throughout the body, including penetration of the blood-brain barrier, and are found in urine, bile, and feces (Johansson, 1992; De Sousa, 2019).

\section{Safety}

Disulfiram is a safe and well-tolerated medication. When side effects are reported, they are generally mild. The higher doses initially used for clinical treatment were associated with more side effects. In the absence of alcohol, disulfiram administered at the currently recommended dosages is well tolerated for months and even years. In case of intolerance, the dose of disulfiram can be lowered (Børup et al., 1992; Brar et al., 2004; Skinner et al., 2014). When taken with alcohol, the disulfiram-alcohol reaction produces serious adverse effects. Therefore, alcohol consumption must be avoided while taking disulfiram. Cutaneous alcohol absorption from hand sanitizers and topical products such as perfumes should not result in a disulfiram-alcohol reaction and risk through inhalation can be mitigated by dispersal of fumes (Brewer and Streel, 2020).

\section{REPURPOSING DISULFIRAM AS AN ANTI-AMEBIC AGENT}

As the years go by, new medical uses for disulfiram are being discovered beyond the inhibition of aldehyde dehydrogenase. As described above, disulfiram is metabolized to ditiocarb which then forms metal complexes. Ditiocarb-metal complexes have anti-cancer effects and are safely given in vivo as oral disulfiram plus copper or zinc supplements. Multiple completed, active, or recruiting clinical trials evaluating disulfiram in combination with divalent metal ion supplement zinc or copper for cancer therapy have shown excellent safety profile (Brar et al., 2004; Grossmann et al., 2013; Nechushtan et al., 2015; Skrott et al., 2017; Ekinci et al., 2019).

A new preclinical study using a mouse model that simulates human amebic colitis showed that oral disulfiram combined with zinc was highly effective in clearing parasites (Figure 1) (Ghosh et al., 2020). Zinc-ditiocarb complex (ZnDTC) had high potency and was active against E. histolytica parasites at low nanomolar concentrations (Ghosh et al., 2020), significantly below the serum and tissue level achieved with disulfiram therapy at recommended doses (Johansson, 1992; Skrott et al., 2017), and 1000 -fold-lower less than the $\mathrm{EC}_{50}$ of metronidazole, the current drug of choice to treat amebiasis.

The Ubiquitin-Proteasomal System (UPS) is responsible for the vast majority of protein degradation within the cell and is conserved in all eukaryotes including protozoans. Disruption of the proteasomal pathway results in accumulation of unwanted and toxic proteins, leading to cell death. Because proteasomemediated degradation is essential for parasite survival, this pathway has become an attractive drug target for protozoan 
A

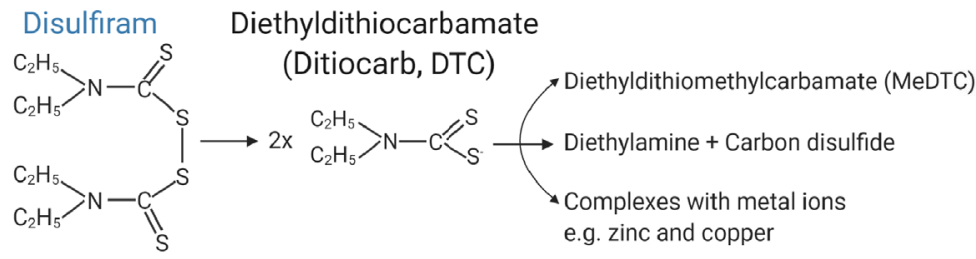

B

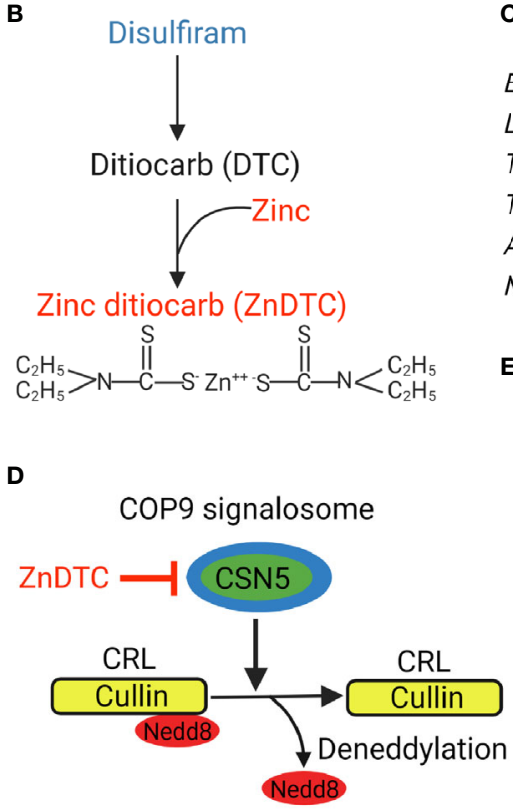

C

$\begin{array}{llll}\text { Entamoeba } & 134 \text { HSHPSYKCWLSGID } & 147 \\ \text { Leishmania } & 163 \text { HTHPGYSCELSGID } & 176 \\ \text { Trypanosoma } & 171 \text { HSHPGYTCFLSGTD } & 184 \\ \text { Toxoplasma } & 164 \text { HSHPGYRCWLSGID } & 177 \\ \text { Acanthamoeba } & 136 \text { HSHPGYGCWLSGID } & 149 \\ \text { Naegleria } & 74 \text { HSHPGYGCWLSGID } & 87\end{array}$

E

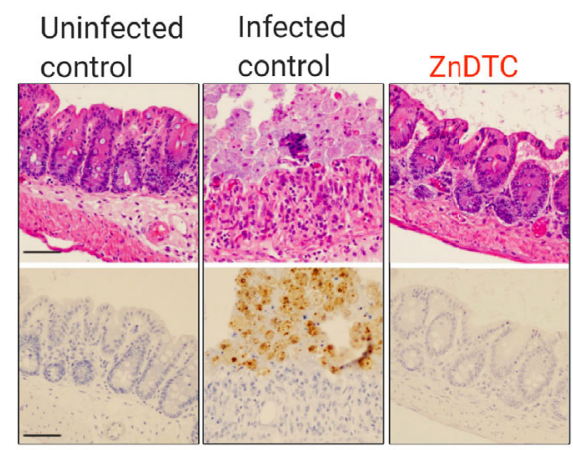

FIGURE 1 | Zinc ditiocarb (ZnDTC), a main metabolite of disulfiram, is potently active against $E$. histolytica parasites in a preclinical animal model. (A) Disulfiram and its metabolites. (B) ZnDTC is formed from the combination of disulfiram and zinc supplement. (C) Multiple sequence alignment of the conserved metalloprotease motif of COP9 signalosome subunit 5 (CSN5) from E. histolytica and other pathogenic parasites (EHI_050500, TGARI_308590, TcCLB.507083.60, LBRM2903_160015100, ACA1_074760, NF0060740). Identical (green), conserved (blue), semi-conserved (pink) and non-conserved residues (red). (D) Schematic of how ZnDTC inhibits cullin deneddylation by the COP9 signalosome. (E) Representative H\&E staining and immunohistochemical analysis of the cecum of infected mice after 5 days of treatment. Specific anti-E. histolytica antibody was used for immunohistochemical staining of trophozoites (brown). Numerous parasites in the infected control, absent in the ZnDTC treated mice and uninfected control. The treatment group received $50 \mathrm{mg} / \mathrm{kg}$ disulfiram plus $1 \mathrm{mg} / \mathrm{kg}$ zinc gluconate. Panels are reproduced from (Ghosh et al., 2020) with permission.

parasites (Khare et al., 2016; Li et al., 2016). The anti-amebic activity of ZnDTC was shown to involve inhibition of the ubiquitin-proteasome pathway (Ghosh et al., 2020).

E3 ubiquitin ligases catalyze the ubiquitination of proteins destined for proteasomal degradation (Cromm and Crews, 2017; Wertz and Wang, 2019). Cullin proteins form the base on which cullin-RING E3 ubiquitin ligases (CRLs) assemble and CRLs make up the majority of E3 ligases. Regulation of CRL activity involves the removal of the ubiquitin-like protein called Nedd8 from cullin proteins by a process called deneddylation. The COP9 signalosome is a multi-subunit protein complex that is responsible for the enzymatic removal of Nedd8 protein from cullins (Cavadini et al., 2016; Mevissen and Komander, 2017). COP9 subunit 5 (CSN5) contains a metalloprotease motif and forms the catalytic core of the COP9 enzyme complex. CSN5 was found to be encoded by Entamoeba histolytica as well as many other clinically relevant protozoans including Trypanosoma,
Leishmania, Toxoplasma, and Naegleria (Ghosh et al., 2018; Ghosh et al., 2020). COP9 activity is essential for Entamoeba histolytica survival. Through computational, genetic, and protein degradation studies, ZnDTC was found to block the metalloprotease activity of CSN5 which disrupted COP9 signalosome deneddylating activity. This caused cullin to be trapped in a neddylated state, disrupting proteasome-mediated degradation, leading to protein accumulation and ultimately cell death (Ghosh et al., 2020).

Additionally, disulfiram may inhibit the glycolytic pathways of E. histolytica (Pineda et al., 2013; Pineda et al., 2015). It should be noted that while disulfiram by itself has shown direct activity in vitro, the drug is rapidly metabolized and therefore would be less effective in vivo if given alone. The metabolites such as ZnDTC metal complexes are stable and would be more practical for clinical use. The safety profile along with preclinical efficacy supports further studies to explore the repurposing of disulfiram 
for amebiasis treatment, which could be the first new amebic treatment available in over 60 years.

\section{REPURPOSING DISULFIRAM AS AN ANTI-PARASITIC AGENT}

While disulfiram, when used by itself, shows varying activity against parasites, in vitro studies have found a greater antiparasitic potency of metabolites when complexed to divalent metal ions such as zinc (ZnDTC) (Peniche et al., 2015; Oliveira et al., 2019). It is plausible then that the metabolites of disulfiram, which remain for a longer duration than the rapidly metabolized disulfiram, may explain the broad range of targets described with this drug in a diverse range of pathogens (Sheppard et al., 2018; Frazier et al., 2019; Lee et al., 2019; Trautmann et al., 2020).

More specifically as an anti-parasitic, in vitro efficacy of the metabolite ZnDTC has also been demonstrated against other protozoan parasites Trypanosoma and Leishmania (Peniche et al., 2015; Oliveira et al., 2019; Ghosh et al., 2020). While the effect of zinc ditiocarb on other parasites is not yet known, COP9 producing protozoans should experience the same effect with ZnDTC (Ghosh et al., 2018; Ghosh et al., 2020). That said, further studies are needed to confirm this theory. Other antiparasitic mechanisms of disulfiram that have been proposed include the inhibition of carbamate kinase and triosephosphate isomerase in Giardia lamblia (Galkin et al., 2014; CastilloVillanueva et al., 2017). Inhibitory effects on growth of Cryptosporidium parvum and Plasmodium falciparum have also been shown (Scheibel et al., 1979; Sarwono et al., 2019). Therefore, ZnDTC might be able to treat a wide range of parasitic infections, one drug for many bugs. The established safety plus in vivo efficacy data support further investigation of ZnDTC, administered as repurposed disulfiram with zinc (Ekinci et al., 2019; Ghosh et al., 2020).

\section{LIMITATIONS ASSOCIATED WITH DISULFIRAM USE}

Alcohol consumption will negatively impact disulfiram adherence. Though, patients prescribed disulfiram need only to abstain from alcohol for 12 hours before initiation of use. Metronidazole too is associated with a similar "disulfiram-like reaction" and alcohol intake is contraindicated with metronidazole use (Cina et al., 1996; Alonzo et al., 2019), yet metronidazole remains one of the most widely used antibiotics worldwide. In addition, the treatment course for amebiasis is relatively short, therefore, only a predicted 5 to 10 -day disulfiram course would be required. All these reasons provide support for disulfiram adherence.

In addition to adults, parasitic infections like amebiasis pose a global health threat to children. Disulfiram was developed and mainly used in adolescent and adult populations (Niederhofer and Staffen, 2003). Therefore, data on pediatric PK/PD properties are additionally needed for age-appropriate dosage.

\section{CONCLUSION}

Protozoan parasites, such as E. histolytica present a major threat to global public health and contribute significantly to morbidity and mortality worldwide. Antibiotic treatment is essential for managing patients infected with these parasites. There is an urgent unmet need to develop effective therapies, given the lack of vaccines, drug resistance, limited efficacy, and toxicity associated with currently available therapies (Field et al., 2017; De Rycker et al., 2018; Shirley et al., 2019). Repurposing existing drugs offers advantages over de novo drug development including cost and time reduction. Disulfiram is already FDAapproved, with a long history of use in medicine and safety information already at hand, and could progress more rapidly through investigation under a repurposed indication. Also, disulfiram is already being repurposed for treating cancer patients. Furthermore, disulfiram is widely available, has a good safety profile, and is an economical and low-cost drug, which could make it a viable economic option for patients in low-income settings (Cvek, 2012). Affordability in low-income countries is an important factor to consider, as parasitic infections such as amebiasis are most prevalent in povertystricken settings. Future acceleration to phase II randomized control trials will allow further investigation of the microbiologic and clinical efficacy of disulfiram as an anti-parasitic.

\section{DATA AVAILABILITY STATEMENT}

The original contributions presented in the study are included in the article/supplementary material. Further inquiries can be directed to the corresponding author.

\section{AUTHOR CONTRIBUTIONS}

D-AS, IS, CW, and SM wrote, edited and/or reviewed the manuscript. All authors contributed to the article and approved the submitted version.

\section{FUNDING}

This work was supported by NIH R01AI026649, K08AI119181, and the Robert Wood Johnson Foundation-Harold Amos Medical Faculty Development Program Award.

\section{ACKNOWLEDGMENTS}

We thank William Petri MD, PhD (University of Virginia) and David Sullivan, MD (Johns Hopkins) for their support. We apologize to those colleagues whose work could not be included due to space limitations. 


\section{REFERENCES}

Alonzo, M. M., Lewis, T. V., and Miller, J. L. (2019). Disulfiram-like Reaction With Metronidazole: An Unsuspected Culprit. J. Pediatr. Pharmacol. Ther. 24, 445449. doi: 10.5863/1551-6776-24.5.445

Andrade, R. M., and Reed, S. L. (2015). New drug target in protozoan parasites: the role of thioredoxin reductase. Front. Microbiol. 6, 975. doi: 10.3389/fmicb.2015.00975

Andrews, K. T., Fisher, G., and Skinner-Adams, T. S. (2014). Drug repurposing and human parasitic protozoan diseases. Int. J. Parasitol.: Drugs Drug Resist. 4, 95-111. doi: 10.1016/j.ijpddr.2014.02.002

Børup, C., Kaiser, A., and Jensen, E. (1992). Long-term Antabuse treatment: tolerance and reasons for withdrawal. Acta Psychiatr. Scand. Suppl. 369, 47-49. doi: 10.1111/j.1600-0447.1992.tb03315.x

Braga, S. S. (2019). Multi-target drugs active against leishmaniasis: A paradigm of drug repurposing. Eur. J. Med. Chem. 183, 111660. doi: 10.1016/j.ejmech.2019.111660

Brar, S. S., Grigg, C., Wilson, K. S., Holder, W. D., Dreau, D., Austin, C., et al. (2004). Disulfiram inhibits activating transcription factor/cyclic AMPresponsive element binding protein and human melanoma growth in a metal-dependent manner in vitro, in mice and in a patient with metastatic disease. Mol. Cancer Ther. 3, 1049-1060.

Brewer, C., and Streel, E. (2020). Is Alcohol in Hand Sanitizers Absorbed Through the Skin or Lungs? Implications for Disulfiram Treatment. Alcohol Alcohol 55, 354-356. doi: 10.1093/alcalc/agaa045

Cappellari, A. M., Rossetti, D., Avignone, S., Scola, E., and Di Cesare, A. (2020). Pediatric Metronidazole-Induced Encephalopathy: A Case Report and Review of the Literature. J. Pediatr. Neurol. doi: 10.1055/s-0040-1716347

Castillo-Villanueva, A., Rufino-González, Y., Méndez, S. T., Torres-Arroyo, A., Ponce-Macotela, M., Martínez-Gordillo, M. N., et al. (2017). Disulfiram as a novel inactivator of Giardia lamblia triosephosphate isomerase with antigiardial potential. Int. J. Parasitol. Drugs Drug Resist. 7, 425-432. doi: 10.1016/j.ijpddr.2017.11.003

Cavadini, S., Fischer, E. S., Bunker, R. D., Potenza, A., Lingaraju, G. M., Goldie, K. N., et al. (2016). Cullin-RING ubiquitin E3 ligase regulation by the COP9 signalosome. Nature 531, 598-603. doi: 10.1038/nature17416

Cina, S. J., Russell, R. A., and Conradi, S. E. (1996). Sudden death due to metronidazole/ethanol interaction. Am. J. Forensic Med. Pathol. 17, 343-346. doi: 10.1097/00000433-199612000-00013

Cordel, H., Prendki, V., Madec, Y., Houze, S., Paris, L., Bouree, P., et al. (2013). Imported amoebic liver abscess in France. PloS Negl. Trop. Dis. 7, e2333. doi: 10.1371/journal.pntd.0002333

Cromm, P. M., and Crews, C. M. (2017). Targeted protein degradation: from chemical biology to drug discovery. Cell Chem. Biol. 24, 1181-1190. doi: 10.1016/j.chembiol.2017.05.024

Cvek, B. (2012). Nonprofit drugs as the salvation of the world's healthcare systems: the case of Antabuse (disulfiram). Drug Discov. Today 17, 409-412. doi: 10.1016/j.drudis.2011.12.010

De Rycker, M., Baragana, B., Duce, S. L., and Gilbert, I. H. (2018). Challenges and recent progress in drug discovery for tropical diseases. Nature 559, 498-506. doi: 10.1038/s41586-018-0327-4

De Sousa, A. (2019). "Disulfiram: The History Behind the Molecule" in Disulfiram (Springer, Singapore), 1-8.

Debnath, A., Ndao, M., and Reed, S. L. (2013). Reprofiled drug targets ancient protozoans: drug discovery for parasitic diarrheal diseases. Gut Microbes 4, 6671. doi: $10.4161 /$ gmic. 22596

Ehrenkaufer, G. M., Suresh, S., Solow-Cordero, D., and Singh, U. (2018). HighThroughput Screening of. Front. Cell Infect. Microbiol. 8, 276. doi: 10.3389/ fcimb.2018.00276

Ekinci, E., Rohondia, S., Khan, R., and Dou, Q. P. (2019). Repurposing disulfiram as an anti-cancer agent: updated review on literature and patents. Recent Patents Anti Cancer Drug Discov. 14, 113-132. doi: 10.2174/1574892814666190514104035

Farha, M. A., and Brown, E. D. (2019). Drug repurposing for antimicrobial discovery. Nat. Microbiol. 4, 565-577. doi: 10.1038/s41564-019-0357-1

Field, M. C., Horn, D., Fairlamb, A. H., Ferguson, M. A., Gray, D. W., Read, K. D., et al. (2017). Anti-trypanosomatid drug discovery: an ongoing challenge and a continuing need. Nat. Rev. Microbiol. 15, 217-231. doi: 10.1038/nrmicro.2016.193

Fink, H. A., Mac Donald, R., Rutks, I. R., Nelson, D. B., and Wilt, T. J. (2002). Sildenafil for male erectile dysfunction: a systematic review and meta-analysis. Arch. Intern. Med. 162, 1349-1360. doi: 10.1001/archinte.162.12.1349
Frazier, K. R., Moore, J. A., and Long, T. E. (2019). Antibacterial activity of disulfiram and its metabolites. J. Appl. Microbiol. 126, 79-86. doi: 10.1111/ jam. 14094

Galkin, A., Kulakova, L., Lim, K., Chen, C. Z., Zheng, W., Turko, I. V., et al. (2014). Structural basis for inactivation of Giardia lamblia carbamate kinase by disulfiram. J. Biol. Chem. 289, 10502-10509. doi: 10.1074/jbc.M114.553123

Ghosh, S., Leaton, L. A., Farr, L., Barfield, A., and Moonah, S. (2018). Interaction between parasite-encoded JAB1/CSN5 and macrophage migration inhibitory factor proteins attenuates its proinflammatory function. Sci. Rep. 8, 1-9. doi: 10.1038/s41598-018-28625-1

Ghosh, S., Farr, L., Singh, A., Leaton, L. A., Padalia, J., Shirley, D. A., et al. (2020). COP9 signalosome is an essential and druggable parasite target that regulates protein degradation. PLoS Pathog. 16, e1008952. doi: 10.1371/ journal.ppat.1008952

Gonzales, M. L. M., Dans, L. F., and Sio-Aguilar, J. (2019). Antiamoebic drugs for treating amoebic colitis. Cochrane Database Syst. Rev. 1, Cd006085. doi: 10.1002/14651858.CD006085.pub3

Grossmann, K. F., Terrazas, M., Khong, H. T., Akerley, W., Kosak, K., Boucher, K., et al. (2013). Phase II study of disulfiram and chelated $\mathrm{Zn}$ for the treatment of disseminated metastatic melanoma (AACR, Washington, DC).

Hung, C. C., Chang, S. Y., and Ji, D. D. (2012). Entamoeba histolytica infection in men who have sex with men. Lancet Infect. Dis. 12, 729-736. doi: 10.1016/ S1473-3099(12)70147-0

Jeelani, G., and Nozaki, T. (2016). Entamoeba thiol-based redox metabolism: a potential target for drug development. Mol. Biochem. Parasitol. 206, 39-45. doi: 10.1016/j.molbiopara.2016.01.004

Johansson, B. (1992). A review of the pharmacokinetics and pharmacodynamics of disulfiram and its metabolites. Acta Psychiatrica Scand. 86, 15-26. doi: 10.1111/j.1600-0447.1992.tb03310.x

Khare, S., Nagle, A. S., Biggart, A., Lai, Y. H., Liang, F., Davis, L. C., et al. (2016). Proteasome inhibition for treatment of leishmaniasis, Chagas disease and sleeping sickness. Nature 537, 229-233. doi: 10.1038/nature19339

Kirkcaldy, R. D., Augostini, P., Asbel, L. E., Bernstein, K. T., Kerani, R. P., Mettenbrink, C. J., et al. (2012). Trichomonas vaginalis antimicrobial drug resistance in 6 US cities, STD Surveillance Network 2009-2010. Emerg. Infect. Dis. 18, 939-943. doi: 10.3201/eid1806.111590

Kotloff, K. L., Nataro, J. P., Blackwelder, W. C., Nasrin, D., Farag, T. H., Panchalingam, S., et al. (2013). Burden and aetiology of diarrhoeal disease in infants and young children in developing countries (the Global Enteric Multicenter Study, GEMS): a prospective, case-control study. Lancet 382, 209-222. doi: 10.1016/S0140-6736(13)60844-2

Kragh, H. (2008). From disulfiram to antabuse: The invention of a drug. Bull. Hist Chem. 33, 82-88.

Kumanan, T., Sujanitha, V., and Sreeharan, N. (2020). Amoebic liver abscess: a neglected tropical disease. Lancet Infect. Dis. 20, 160-162. doi: 10.1016/S14733099(19)30696-6

Kumar, N., Sundriyal, D., Walia, M., and Trisal, D. (2013). Metronidazole-induced fixed drug eruption. BMJ Case Rep. 2013. doi: 10.1136/bcr-2013-200470

Lee, S. A., Elliott, J. H., Mcmahon, J., Hartogenesis, W., Bumpus, N. N., Lifson, J. D., et al. (2019). Population Pharmacokinetics and Pharmacodynamics of Disulfiram on Inducing Latent HIV-1 Transcription in a Phase IIb Trial. Clin. Pharmacol. Ther. 105, 692-702. doi: 10.1002/cpt.1220

Leitsch, D. (2015). Drug Resistance in the Microaerophilic Parasite. Curr. Trop. Med. Rep. 2, 128-135. doi: 10.1007/s40475-015-0051-1

Li, H., O'donoghue, A. J., Van Der Linden, W. A., Xie, S. C., Yoo, E., Foe, I. T., et al. (2016). Structure- and function-based design of Plasmodium-selective proteasome inhibitors. Nature 530, 233-236. doi: 10.1038/nature16936

Liu, J., Platts-Mills, J. A., Juma, J., Kabir, F., Nkeze, J., Okoi, C., et al. (2016). Use of quantitative molecular diagnostic methods to identify causes of diarrhoea in children: a reanalysis of the GEMS case-control study. Lancet 388, 1291-1301. doi: 10.1016/S0140-6736(16)31529-X

Lozano, R., Naghavi, M., Foreman, K., Lim, S., Shibuya, K., Aboyans, V., et al. (2012). Global and regional mortality from 235 causes of death for 20 age groups in 1990 and 2010: a systematic analysis for the Global Burden of Disease Study 2010. Lancet 380, 2095-2128. doi: 10.1016/S0140-6736(12)61728-0

Marie, C., and Petri, W. A. Jr. (2013). Amoebic dysentery. BMJ Clin. Evid 2013.

Martínez-Castillo, M., Pacheco-Yepez, J., Flores-Huerta, N., Guzmán-Téllez, P., Jarillo-Luna, R. A., Cárdenas-Jaramillo, L. M., et al. (2018). Flavonoids as a 
natural treatment against Entamoeba histolytica. Front. Cell. Infect. Microbiol. 8, 209. doi: $10.3389 /$ fcimb. 2018.00209

Mazumdar, G., and Shome, K. (2014). Stevens-Johnson syndrome following use of metronidazole in a dental patient. Indian J. Pharmacol. 46, 121-122. doi: 10.4103/0253-7613.125193

Mevissen, T. E., and Komander, D. (2017). Mechanisms of deubiquitinase specificity and regulation. Annu. Rev. Biochem. 86, 159-192. doi: 10.1146/ annurev-biochem-061516-044916

Murray, C. J., Vos, T., Lozano, R., Naghavi, M., Flaxman, A. D., Michaud, C., et al. (2012). Disability-adjusted life years (DALYs) for 291 diseases and injuries in 21 regions 1990-2010: a systematic analysis for the Global Burden of Disease Study 2010. Lancet 380, 2197-2223. doi: 10.1016/S0140-6736(12)61689-4

Nagaraja, S., and Ankri, S. (2019). Target identification and intervention strategies against amebiasis. Drug Resist. Updates 44, 1-14. doi: 10.1016/j.drup.2019.04.003

Nechushtan, H., Hamamreh, Y., Nidal, S., Gotfried, M., Baron, A., Shalev, Y. I., et al. (2015). A phase IIb trial assessing the addition of disulfiram to chemotherapy for the treatment of metastatic non-small cell lung cancer. Oncologist 20, 366-367. doi: 10.1634/theoncologist.2014-0424

Niederhofer, H., and Staffen, W. (2003). Comparison of disulfiram and placebo in treatment of alcohol dependence of adolescents. Drug Alcohol Rev. 22, 295297. doi: $10.1080 / 0959523031000154436$

Oliveira, J. W. D. F., Rocha, H., De Medeiros, W. M. T. Q., and Silva, M. S. (2019). Application of Dithiocarbamates as Potential New AntitrypanosomatidsDrugs: Approach Chemistry, Functional and Biological. Molecules 24, 2806. doi: $10.3390 /$ molecules 24152806

Paulish-Miller, T. E., Augostini, P., Schuyler, J. A., Smith, W. L., Mordechai, E., Adelson, M. E., et al. (2014). Trichomonas vaginalis metronidazole resistance is associated with single nucleotide polymorphisms in the nitroreductase genes ntr4Tv and ntr6Tv. Antimicrob. Agents Chemother. 58, 2938-2943. doi: 10.1128/AAC.02370-13

Peniche, A. G., Renslo, A. R., Melby, P. C., and Travi, B. L. (2015). Antileishmanial Activity of Disulfiram and Thiuram Disulfide Analogs in an Ex Vivo Model System Is Selectively Enhanced by the Addition of Divalent Metal Ions. Antimicrob. Agents Chemother. 59, 6463-6470. doi: 10.1128/AAC.05131-14

Pineda, E., Encalada, R., Olivos-García, A., Néquiz, M., Moreno-Sánchez, R., and Saavedra, E. (2013). The bifunctional aldehyde-alcohol dehydrogenase controls ethanol and acetate production in Entamoeba histolytica under aerobic conditions. FEBS Lett. 587, 178-184. doi: 10.1016/j.febslet.2012.11.020

Pineda, E., Encalada, R., Vázquez, C., Néquiz, M., Olivos-García, A., Moreno-Sánchez, R., et al. (2015). In vivo identification of the steps that control energy metabolism and survival of Entamoeba histolytica. FEBS J. 282, 318-331. doi: 10.1111/febs.13131

Pushpakom, S., Iorio, F., Eyers, P. A., Escott, K. J., Hopper, S., Wells, A., et al. (2019). Drug repurposing: progress, challenges and recommendations. Nat. Rev. Drug Discov. 18, 41-58. doi: 10.1038/nrd.2018.168

Reus, V. I., Fochtmann, L. J., Bukstein, O., Eyler, A. E., Hilty, D. M., HorvitzLennon, M., et al. (2018). The American Psychiatric Association Practice Guideline for the Pharmacological Treatment of Patients With Alcohol Use Disorder. Am. J. Psychiatry 175, 86-90. doi: 10.1176/appi.ajp.2017.1750101

Rogawski, E. T., Platts-Mills, J. A., Seidman, J. C., John, S., Mahfuz, M., Ulak, M., et al. (2017). Use of antibiotics in children younger than two years in eight countries: a prospective cohort study. Bull. World Health Organ 95, 49-61. doi: 10.2471/BLT.16.176123

Sarwono, A. E. Y., Mitsuhashi, S., Kabir, M. H. B., Shigetomi, K., Okada, T., Ohsaka, F., et al. (2019). Repurposing existing drugs: identification of irreversible IMPDH inhibitors by high-throughput screening. J. Enzyme Inhib. Med. Chem. 34, 171-178. doi: 10.1080/14756366.2018.1540474

Scheibel, L. W., Adler, A., and Trager, W. (1979). Tetraethylthiuram disulfide (Antabuse) inhibits the human malaria parasite Plasmodium falciparum. Proc. Natl. Acad. Sci. U. S. A. 76, 5303-5307. doi: 10.1073/pnas.76.10.5303

Schwebke, J. R., and Barrientes, F. J. (2006). Prevalence of Trichomonas vaginalis isolates with resistance to metronidazole and tinidazole. Antimicrob. Agents Chemother. 50, 4209-4210. doi: 10.1128/AAC.00814-06
Sheppard, J. G., Frazier, K. R., Saralkar, P., Hossain, M. F., Geldenhuys, W. J., and Long, T. E. (2018). Disulfiram-based disulfides as narrow-spectrum antibacterial agents. Bioorg. Med. Chem. Lett. 28, 1298-1302. doi: 10.1016/ j.bmcl.2018.03.023

Shirley, D.-A., and Moonah, S. (2016). Fulminant Amebic Colitis after Corticosteroid Therapy: A Systematic Review. PLoS Negl. Trop. Dis. 10, e0004879. doi: 10.1371/journal.pntd.0004879

Shirley, D. T., Farr, L., Watanabe, K., and Moonah, S. (2018). A Review of the Global Burden, New Diagnostics, and Current Therapeutics for Amebiasis. Open Forum Infect. Dis. 5, ofy161. doi: 10.1093/ofid/ofy161

Shirley, D. T., Watanabe, K., and Moonah, S. (2019). Significance of amebiasis: 10 reasons why neglecting amebiasis might come back to bite us in the gut. PLoS Negl. Trop. Dis. 13, e0007744. doi: 10.1371/journal.pntd.0007744

Skinner, M. D., Lahmek, P., Pham, H., and Aubin, H. J. (2014). Disulfiram efficacy in the treatment of alcohol dependence: a meta-analysis. PLoS One 9, e87366. doi: 10.1371/journal.pone.0087366

Skrott, Z., Mistrik, M., Andersen, K. K., Friis, S., Majera, D., Gursky, J., et al. (2017). Alcohol-abuse drug disulfiram targets cancer via p97 segregase adaptor NPL4. Nature 552, 194-199. doi: 10.1038/nature25016

Sørensen, C., Karlsson, W., Amin, F., and Lindelof, M. (2018). Metronidazoleinduced encephalopathy: a systematic review. J. Neurol. 267, 1-13. doi: 10.1007/s00415-018-9147-6

Suh, J. J., Pettinati, H. M., Kampman, K. M., and O'brien, C. P. (2006). The status of disulfiram: a half of a century later. J. Clin. Psychopharmacol. 26, 290-302. doi: 10.1097/01.jcp.0000222512.25649.08

Torgerson, P. R., Devleesschauwer, B., Praet, N., Speybroeck, N., Willingham, A. L., Kasuga, F., et al. (2015). World Health Organization Estimates of the Global and Regional Disease Burden of 11 Foodborne Parasitic Disease: A Data Synthesis. PLoS Med. 12, e1001920. doi: 10.1371/journal.pmed.1001920

Trautmann, A., Gascan, H., and Ghozzi, R. (2020). Potential Patient-Reported Toxicities With Disulfiram Treatment in Late Disseminated Lyme Disease. Front. Med. 7. doi: 10.3389/fmed.2020.00133

Van Den Broucke, S., Verschueren, J., Van Esbroeck, M., Bottieau, E., and Van Den Ende, J. (2018). Clinical and microscopic predictors of Entamoeba histolytica intestinal infection in travelers and migrants diagnosed with Entamoeba histolytica/dispar infection. PLoS Negl. Trop. Dis. 12, e0006892. doi: 10.1371/journal.pntd.0006892

Weiss, D. J., Lucas, T. C. D., Nguyen, M., Nandi, A. K., Bisanzio, D., Battle, K. E. et al. (2019). Mapping the global prevalence, incidence, and mortality of Plasmodium falciparum 2000-17: a spatial and temporal modelling study. Lancet 394, 322-331. doi: 10.1016/S0140-6736(19)31097-9

Wertz, I. E., and Wang, X. (2019). From discovery to bedside: targeting the ubiquitin system. Cell Chem. Biol. 26, 156-177. doi: 10.1016/ j.chembiol.2018.10.022

Woodruff, B. K., Wijdicks, E. F., and Marshall, W. F. (2002). Reversible metronidazole-induced lesions of the cerebellar dentate nuclei. N. Engl. J. Med. 346, 68-69. doi: 10.1056/NEJM200201033460117

Yamamoto, K., Yanagawa, Y., Oka, S., and Watanabe, K. (2020). Two cases of endoscopically diagnosed amebic colitis treated with paromomycin monotherapy. PLoS Negl. Trop. Dis. 14, e0008013. doi: 10.1371/journal.pntd.0008013

Conflict of Interest: The authors declare that the research was conducted in the absence of any commercial or financial relationships that could be construed as a potential conflict of interest.

Copyright (c) 2021 Shirley, Sharma, Warren and Moonah. This is an open-access article distributed under the terms of the Creative Commons Attribution License (CC BY). The use, distribution or reproduction in other forums is permitted, provided the original author(s) and the copyright owner(s) are credited and that the original publication in this journal is cited, in accordance with accepted academic practice. No use, distribution or reproduction is permitted which does not comply with these terms. 